\title{
Geriatric emergencies seen in the Casualty Department
}

\author{
R. S. Stevens \\ M.D., M.R.C.P. \\ Consultant Geriatrician, South-East Kent, \\ St Mary's Hospital, Etchinghill, Folkestone
}

\begin{abstract}
Medical emergencies formed only $6 \%$ of 30,000 new attendences in a large Casualty Department (Garden, 1965). These comprised poisoning, epilepsy, alcoholic or diabetic coma, coronary occlusion, cerebral catastrophe and acute respiratory conditions. Only a small proportion of these cases would be geriatric emergencies, which, as I have observed elsewhere (Stevens, 1966), are common in general practice; but many geriatric patients would be included in the $82 \%$ attending for accidents and surgical emergencies.
\end{abstract}

The emergencies which elderly patients may present in the Casualty Department differ from those encountered in other age-groups in degree rather than in kind but failure to seek and to recognize these differences can lead to misdiagnosis and even to failure to recognize that an old person is ill. The mode of presentation and the underlying significance of many acute conditions in old age form a fascinating and fruitful subject for study.

The first problem with many geriatric patients is that of communication; even in the most dire emergency some medical history is desirable. A simple ear trumpet and a writing pad should be available in every Casualty Department. One rarely meets the complete impasse of total deafness and blindness, but it may be possible even then to communicate by tracing capital letters with a finger-tip on the palm of the patient's hand.

Physicians in general- and hospital-practice agree that the commonest geriatric emergencies arise from cardiac disease, whether revealed by acute left ventricular failure or by myocardial infarction presenting in this or other forms. Arteriosclerotic and degenerative heart disease is the commonest cause of death in this country. Florence McKeown (1965) analysed the autopsy findings of 1500 patients aged 70 years or more at death ; she found that 310 of this series of deaths were caused by disease of the cardiovascular system and $200(13 \%$ of the series) were due to coronary disease. Despite multiple aetiological factors she emphasizes the contribution of coronary disease to the development of heart failure in old age, and states the whole pattern of cardiac pathology at this period of life is dominated by coronary disease'.

The patient with acute left ventricular failure may require urgent treatment in the Department. An immediate intravenous injection of morphine $15 \mathrm{mg}$ (or combined with cyclizine $50 \mathrm{mg}$, as 'cyclimorph'), should be followed by intravenous injection of frusemide $40 \mathrm{mg}$ (Stokes \& Nunn, 1964) or, in some cases, ethacrynic acid $50 \mathrm{mg}$ (Ledingham, 1964). Aminophylline $0.25 \mathrm{~g}$ mayo also be given; the patient should subsequently be? digitalized under careful control and regular review. As soon as possible an electrocardiogram should be taken to assist exact diagnosis and as a guide to treatment and prognosis.

Myocardial infarction may present in the elderly with the classical symptoms of anginal pain of typical distribution lasting for $\frac{1}{2} \mathrm{hr}$ to several hours, but the more obscure symptoms of onset are often overlooked. Coronary artery occlusion associated with paroxysmal dyspnoea without anginal pain has been recognized for nearly a century. Fifty years ago Gallavardin observed that elderly patients might simply present with prostration, and rapidly develop cardiac failure. Sudden changes of rhythm or inexplicably low blood-pressure readings may provide important clues. The possible association of myocardial infarction with hemiplegia complicates diagnosis in some cases. Two case-histories illustrate how such problems may present in a Casualty Department.

A woman aged 77 was sent to the Casualty Department because she was suspected of having fractured a femur on falling out of bed. No fracture was found but the history revealed several years' angina of effort culminating 2 weeks previously in a prolonged attack of severe retrosternal 
and epigastric pain, radiating down both arms, and accompanied by vomiting, and causing the patient, who lived alone, to remain in bed. An electrocardiogram showed recent septal infarction and she was admitted. Autopsy 10 weeks later showed an apical myocardial infarction involving the septum.

A woman aged 85 , living alone, 'felt dizzy and fell down', injuring her right wrist. In the Casualty Department a Colles' fracture was diagnosed and a dorsal plaster slab was applied. The patient was sent home without further investigation of the cause of the fall. One week later, because of the splinted and painful wrist, she seemed incapable of looking after herself and was admitted for geriatric assessment. A simple history of breathlessness and swollen feet for several months, combined with her appearance and state of mental confusion prompted the investigation of the blood (haemoglobin $38 \% 5.6 \mathrm{~g} / 100 \mathrm{ml}$, absolute values indicating iron-deficiency). The pulse was regular, a presystolic gallop rhythm was audible, B.P. $120 / 70 \mathrm{mmHg}$. An electrocardiogram showed right bundle branch block with evidence of recent extensive anterior myocardial infarction. She rapidly recovered on treatment with iron and diuretics. She was discharged to a Welfare Home and at follow-up 4 months from onset she appeared well.

In a 3-year study Thould (1965) noticed the rarity of cases of acute coronary disease admitted to a geriatric hospital: $3 \%$ of a total of 1300 admissions; these he contrasted with the number admitted for recent cerebrovascular accidents, $12 \%$ of the total admissions. Fewer than half the patients suffered pain, about half were dyspnoeic, a few complained only of tiredness, weakness, lethargy, or painless vomiting. McKeown observed that, excluding patients who died suddenly, 57\% of her series had suffered pain, often mild; in at least $15 \%$ the diagnosis was not made clinically because of atypical presentation. Fullerton (1965) surveyed 1713 autopsies in patients aged 70 and over; of 543 cardiovascular deaths, 138 were caused by coronary thrombosis; there were 152 cases of cerebrovascular accidents. Pomerance (1965) observed that half of the deaths from disease of the circulatory system occur in patients aged over 75 years, and that cardiovascular disease accounts for $40 \%$ of deaths over that age. She studied the hearts of 370 persons who died aged 75 years or more; of these 162 had died in congestive cardiac failure, which she found to have been caused by ischaemic heart disease in nearly $50 \%$ of cases.

Although it is not common, dissecting aneurysm of the aorta may sometimes be difficult to dis- tinguish clinically from myocardial infarction; much depends on the site and extent of dissection, but pain may radiate into the lumbar region, the abdomen or into the legs; the electrocardiogram may be normal.

Sudden alterations of cardiac rate or rhythm are especially prone in elderly patients to cause syncopal symptoms; patients with Stokes-Adams attacks caused by complete heart block should be admitted to hospital for assessment of possible treatment by long-term endocardial pacing or by long-acting isoprenaline (Bluestone et al., 1965). It has become increasingly important for the Casualty Officer to recognize alterations of cardiac rate or rhythm caused by excessive dosage with digitalis, to which elderly people are particularly sensitive, especially in the presence of a lowered serum potassium level, as may occur with the uncontrolled use of thiazide diuretics. Schott (1964) analysed 2000 consecutive electrocardiograms in hospital ; 597 tracings referred to 348 patients who had had digitalis within the previous fortnight. Seventy-eight per cent of the patients were aged over 61 years and $52 \%$ over 71 years. The records suggested over-digitalization in forty-two cases $(12 \%)$; the death of nine patients $(21 \%)$ was believed to be associated with digitalis. The smaller tolerance and requirements of elderly people, the use of digitalis only when absolutely indicated, and the manifestations of toxicity in refractory or worsening cardiac failure are emphasized. Dall (1965) has observed that elderly patients are not only peculiarly prone to digitalis intoxication but are liable to its rarer manifestations; arrhythmia without bigeminal rhythm or bradycardia, paradoxical increase in heart rate, or refractory cardiac failure; mental confusion or even psychosis; and, rarely, gynaecomastia; in any case of doubt digitalis therapy should be suspended until investigations are completed.

Much has been written about temporal arteritis, giant-cell arteritis, or the 'arteritis of the elderly', which should always be considered when old people complain of pains and tenderness about the head and neck, as on mastication, especially if the erythrocyte sedimentation rate is raised. Paulley \& Hughes (1960) list fourteen separate modes of presentation, several of which might be seen in the Casualty Department; this disease must be diagnosed early if the dread complication of blindness is to be prevented; this ischaemic optic neuritis' occurs in about one-third of untreated cases but practically not at all in cases treated with steroids.

Sudden loss of vision may also be due to retinal vascular occlusion. In a series of 146 cases Ellis et al. (1964) found the obstruction to be arterial in 
forty cases and venous in 146 cases. In $56 \%$ of the cases at least one other (often previously unsuspected) medical condition was found, including hypertension, ischaemic disease elsewhere, temporal arteritis, valvular heart disease, diabetes and carcinoma.

\section{Neoplasms}

Malignancy caused death in $20 \%$ of McKeown's series; seventy-three of 302 fatal cases were due to carcinoma of the large intestine. Many emergencies may be symptomatic of previously unsuspected malignant disease in elderly people. Haemorrhage, acute obstruction or perforation of the gastro-intestinal tract, or a pathological fracture are examples. Cerebral neoplasms, whether primary or secondary may present with the sudden onset of incontinence, epilepsy, mental confusion, or falls. We must beware the too ready attribution of such symptoms to arteriosclerotic cerebral degeneration without ensuring the fullest possible history, medical examination and assessment. Especially must we eschew the attribution of such symptoms to 'old age'; it is 'the fundamental right of the geriatric patient to be provided with an accurate diagnosis, a considered prognosis, and the means of effective treatment' (Agate, 1963).

\section{Cerebrovascular accidents}

A Casualty Officer, with an unconscious hemiplegic patient in his Department, and only one bed empty in a general medical ward, recently telephoned to enquire if this unconscious patient with a stroke was 'too acute' for a geriatric assessment ward. Geriatric medicine in this country is no longer concerned with what Adams (1964) has called 'the bogus expedient' of distinguishing between 'acute' and 'chronic cases', but with the comprehensive medical needs of all elderly sick people. In particular there is much to be said for the direct admission, whenever possible, of patients with stroke illness to geriatric wards.

Carter (1962) states that hemiplegia due to cerebral infarction caused by occlusion of the carotid-middle-cerebral axis is ten times more common than the pattern of hindbrain and midbrain infarction caused by lesions of the vertebrobasilar axis.

In cerebral embolism the onset is sudden, whereas in cerebral thrombosis it is classically described as more gradual and jerky. Intracerebral haemorrhage may be the concluding event in general vascular disease and hypertension. Strokes associated with haematomas or cerebral tumours tend to develop gradually. It is important to recognize cases in which painless myocardial infarction and acute cerebral vascular disease occur simultaneously (Heron \& Anderson, 1965).
The pattern of cerebrovascular disease in England and Wales has been reversed in the past 30 years; there are now more deaths from cerebral infarction than from cerebral haemorrhage (Yates, 1964). Although their study concerned patients under 55 years old, Prineas \& Marshall (1966) found that patients with diastolic blood pressures below $110 \mathrm{mmHg}$ (omitting cases associated with myocardial infarction or gastro-intestinal haemorrhage) tended to sustain large cortical and subcortical lesions and a poor degree of recovery, whereas those with higher diastolic blood pressures showed small, deeply situated lesions, a low incidence of arterial lesions demonstrated by angiography, and little residual disability. Adams (1965) also found that the prognosis was better for hypertensive than for normotensive hemiplegics.

Attacks of transient cerebral ischaemia, lasting less than $1 \mathrm{hr}$, may cause a patient to be brought to the Casualty Department. It is wise to admit these patients for a short period of observation. In a series of eighty-two such patients observed by Acheson \& Hutchinson (1964) a stroke developed in forty-two patients. When followed for an average period of 40 months, fifty-seven of the eighty-two patients were in normal health; eighteen were moderately or severely disabled of had died from cerebrovascular disease; seven had died from other causes. None was treated witk anticoagulants, which in other hands (Pearce et al., 1965 ; Marshall \& Reynolds, 1965) have given conflicting results. Anticoagulant therapy now seems to have no place in the treatment of completed strokes (Editorial, Lancet, 1966).

If rehabilitation of strokes is started early, relatively few patients need long-term care (ExtonSmith, 1959). Wherever the teams necessary for rehabilitation exist patients should be encouraged to use them. Relatives should be warned of the uncertainty of prognosis whether for survival or for restoration of function; any effects of the stroke on the patient's emotions and personality should be explained; everybody concerned should contribute to the large store of confidence and understanding necessary to support the patient in the arduous and lengthy process of rehabilitation.

\section{Respiratory emergencies}

Apart from the rare drama of acute asphyxia, as in laryngeal obstruction by a foreign body, the treatment of which is not modified by the patient's age, respiratory emergencies in elderly patients are chiefly associated with infection. It is notorious that respiratory infection presents insidiously in old people, as anything but an emergency; but toxaemia or anoxia may cause an acute confusional state and incontinence or a fall may lead 
to the discovery of pneumonia. Although specific pneumonias occur in old age yet the commonest are 'aspiration pneumonias' (Woodford-Williams, 1966), especially in patients suffering from chronic bronchitis, cardiac, renal, or cerebral disease, malnutrition, shock, hypothermia and immobilization. An increased respiratory rate may be the principal clue to diagnosis.

When home nursing is impracticable the patient should be admitted to hospital sooner rather than later, to ensure effective short-term care for the emergency, followed by support (visits by Home Help, District Nurse, etc.) for the patient on return home and during convalescence.

\section{Falls}

Many geriatric emergencies seen in the Casualty Department are associated with falls, a special complication of old age, dreaded alike by those who care for the elderly and by old people themselves.

In 1964 in England and Wales 5314 people died from accidental falls (Registrar General, 1966). Of these $4404(83 \%)$ were aged over 65 years; $75 \%$ of all falls on stairs (595 of 787) were in elderly persons. Also in 1964, 327 of 684 deaths from burns were of persons aged 65 years and over $(48 \%)$.

Sheldon (1960) classified the causes of 500 falls in 202 persons over 50 years old. There were 171 falls $(34 \%$ of the total) in 125 individuals. Onethird of falls sustained by old people at home were accidental and one-third of these occurred on stairs. One-quarter of the falls were classified as 'drop attacks', in which the patient suddenly, without warning, and without loss of consciousness, drops to the ground. Sheldon (1963) has also shown that the control of stance is related to age and deteriorates after the fifth decade of life.

Brain (1964) stressed the peculiar propensity of Parkinsonian patients to fall. Among other causes he mentioned visual or motor inattention, sedative drugs, mental confusion at night, and the obstructive effects of cervical spondylosis on the vertebrobasilar circulation. Howell (1963) has classified common causes of falls as general or local muscle weakness, lesions of the pyramidal or extrapyramidal tracts, or of the posterior columns, syncopal and 'premonitory' falls and 'drop attacks'.

Epilepsy appears to be much commoner as a cause of falls in old people than is generally recognized. Fine (1966) has described 40 aged patients suffering from epileptic syndromes and he has (Fine, 1967) drawn special attention to posthemiplegic epilepsy in the elderly.

We must never be content to treat the fall alone but must always be concerned to discover the basic cause for falling in each individual.

\section{Surgical emergencies}

Surgery for acute abdominal conditions, whether inflammatory or obstructive, is not contraindicated by old age alone; all those who discuss surgery in old age agree that it is essential to operate early.

Constipation may rarely cause perforation of the colon in old people; faecal impaction of the rectum is a common cause of spurious diarrhoea, which may lead to the belief that an individual is incontinent. The condition, easily confirmed by digital examination, is treated by physical removal of the obstructing faecal mass; some days may elapse before normal sphincter control is regained; recurrences should be prevented.

The emergencies of perforation or haemorrhage of the gastro-intestinal tract may occur with malignant ulcers or, even in elderly people, with benign peptic ulcers, which may be enormous. Strange (1963) described a series of seventy-eight patients over the age of 60 years with giant ulcers (3-12 cm in diameter), the symptoms of which may simulate gastric carcinoma; thirty-seven of the patients were admitted to hospital with acute haemorrhage, and four with perforation. Immediate treatment with blood transfusion is advised and early, rather than late, operation.

The possibility of acute glaucoma should be considered in an elderly patient who complains of headache, vomiting and malaise ; if the cornea appears hazy and the pupil vertically oval and fixed, urgent surgical advice is needed.

Fry (1964) studied 738 emergency surgical admissions aged 70 or more years, of whom 343 $(47.5 \%)$ were submitted to surgery (162 within $6 \mathrm{hr}$ ), resulting in $23.5 \%$ mortality. Sixty-three patients were too ill for surgery ( $70 \%$ mortality); 332 were treated conservatively ( $18.5 \%$ mortality). The study was mainly concerned with postoperative mortality and morbidity from respiratory and cardiovascular disease. Patients with ischaemic heart disease without congestive failure and those with less severe degrees of chronic respiratory disease were not adversely affected by the anaesthetic and operation.

\section{Accidental hypothermia}

Accidental hypothermia is defined in a British Medical Association Memorandum (1964) as existing when the body temperature is below $95^{\circ} \mathrm{F}$ $\left(35^{\circ} \mathrm{C}\right)$. Taylor (1964) has recorded temperatures down to $-14^{\circ} \mathrm{C}$ in the bedrooms and kitchens of elderly people in Somerset. Victims of this condition may arrive in the Casualty Department 
mentally confused or comatose. The condition is caused by a mixture of exogenous factors (exposure to cold) and endogenous factors such as cerebrovascular accidents, pneumonia, myocardial infarction, mental impairment and drugs, especially phenothiazine tranquillizers. Endocrine factors, myxoedema and hypopituitarism rarely occur. In cold weather a history of progressive confusion, slurred speech, ataxia, involuntary movements, pale or cyanosed skin, which may appear puffy, should prompt the clinician to suspect this diagnosis, which may be supported by placing the hand on the abdomen or some other normally warm area of the body. Low-reading thermometers should be available in all Casualty Departments.

The condition is an emergency requiring hospital treatment: slow warming, correction of dehydration, antibiotics, corticosteroids, oxygen and, if specifically indicated, thyroid hormone therapy.

A Committee of the Royal College of Physicians (1966) has reported on a survey of 126 hypothermic patients admitted in 3 months (February to April 1965) to ten hospital groups in England and Scotland. The problem particularly concerns children under 1 year $(82 \cdot 2$ hypothermic admissions per thousand total admissions of this age), and adults over 75 years $(17 \cdot 4$ per thousand admissions at this age), but may occur at any age. The condition is directly associated with environmental temperature. The mortality is high whether the condition is, or is not, complicated by cardiovascular disease, diabetes, drugs or other factors. Forty-seven of the 126 patients died $(37 \%)$.

\section{Psychiatric disorders}

Mental confusion may be symptomatic of many physical disorders. Cardiac failure, febrile illness, strokes, respiratory disease, surgical emergencies, neoplasms, hypothermia and endocrine dysfunction have been mentioned. Uraemia and anaemia are other well-known and common causes. Dawson \& Donald (1966) found a low serum vitamin $B_{12}$ level in twenty-six of 100 patients aged over 70 years and they observed a high incidence of psychiatric abnormality in this group.

Depressive illness is the most important cause of suicide (Miller, 1967) and is commoner in later life. The elderly patient may be preoccupied with death, convinced (even against the facts) of poverty, and suffer horrifying hallucinations.

A general practice survey by Watts et al. (1964) showed the high incidence of mental illness in old age. Of 5566 deaths from suicide in England and Wales in 1964, $1412(25 \%)$ were of persons aged over 65 ; of 3412 deaths from carbon monoxide poisoning, $1320(40 \%)$ were in persons over this age. Suicide is related to isolation, retirement, lack of employement and loss of status; depression and the organic psychoses are closely associated factors and critical situations may be precipitated by physical illness or bereavement (Sainsbury, 1962).

The Casualty Officer who finds himself in doubt about the relative importance of these precipitating factors in an individual case may solve the problem by admitting the patient to a combined psycho-geriatric assessment ward, where the psychiatrist and geriatrician can together evolve the correct balance of physical and psychiatric treatment appropriate to the patient's needs.

\section{Social emergencies}

We must distinguish between (a) the purely social emergency, when an old person may be brought to the Casualty Department because of the sudden death or illness of a sole supporting relative or friend, or because of physical disaster such as flooding or fire, and (b) the social breakdown caused by an old person's illness; it is not rare for such an illness first to come to the notice of doctors when a relative suddenly declares the strain of caring for the old person to be intoler able. In either case the Casualty Officer should examine the elderly patient before deciding whether to seek the patient's admission to a Welfare Home or to a geriatric ward.

Finally, there is the problem of cumulative selfneglect in an elderly person, which may suddenly present as an emergency.

A woman aged 79 was brought to the Casualty Department at 03.00 hours. She had been seen lying helpless on the floor at home and was suspected to have a fractured femur. She lived in utter squalor and had refused all offers of help ; only 2 days earlier she had refused admission to a geriatric hospital. She was exceedingly dirty: her matted hair and adhering clothes were cut off in the Casualty Department. There were necrotic pressure areas at several points, an extensive sloughing pressure sore on the left buttock, and a deep wound of one knee, exposing muscletendons, where a string-garter had been worn, presumably for several weeks. Long, curled and infected toenails completed the picture of neglect. The heart, lungs and abdomen appeared normal. $\mathrm{X}$-ray revealed no fracture. Investigations revealed neither anaemia nor uraemia. She proved to be incontinent, confused and demented. Three months later she was gradually regaining mobility and the pressure ulcers were almost healed.

In a period of 8 months I visited 514 patients in their homes. Eight were living in extreme 
squalor, as defined elsewhere (Stevens, 1963). Two patients were relatively young and showed evidence of very prolonged self-neglect; both were suffering from mental disorders and they were admitted to psychiatric hospitals. The average age of six patients was 83 years and they all had evidence of physical disease and some degree of senile dementia; the prognosis was universally bad.

Macmillan \& Shaw (1966) studied a series of seventy-two such cases in 3 years, with a fourth follow-up year at the end of which five of twelve men and thirty-one of sixty women had died. Over half the patients presented psychotic symptoms, but there was no evidence of psychosis in thirty-four.

The authors concluded that the rejection of the usual standards of personal and environmental hygiene is an active and positive reaction and not a passive deterioration; these patients resist all offers of help, and their condition constitutes a syndrome, to which such factors as isolation, a type of personality, bereavement, and alcoholism contribute.

\section{References}

Acheson, J. \& Hutchison, E.C. (1964) Observations on the natural history of transient cerebral ischaemia. Lancet, ii, 871.

ADAMS, G.F. (1964) Clinical undertaking. Lancet, i, 1055.

ADAMs, G.F. (1965) Prospects for patients with strokes, with special reference to the hypertensive hemiplegic. Brit. med. J. ii, 253.

Agate, J. (1963) The Practice of Geriatrics, p. 441. Heinemann, London.

Bluestone, R., Davies, G., Harris, A., Leatham, A. \& SidDONs, H. (1965) Long-term endocardial pacing for heart block. Lancet, ii, 307.

BraIN, LORD (1964) Cerebrovascular disease as a cause of falls in the elderly. Geront. clin. 6, 167.

British Medical Association (1964) Accidental hypothermia in the elderly. Brit. med.J. ii, 1255.

CARTER, A.B. (1962) The Medical Annual, p. 9. John Wright, Bristol.

DALL, J.L.C. (1965) Digitalis intoxication in elderly patients. Lancet, i, 194.

Dawson, A.A. \& Donald, D. (1966) The serum vitamin $\mathrm{B}_{12}$ in the elderly. Geront. clin. 8, 220.

EDITORIAL (1966) Anticoagulants and cerebral infarction. Lancet, i, 245.

Ellis, C.J., Hamer, D.B., Hunt, R.W., Lever, A.F., Lever, R.S., Peart, W.S. \& Walker, S.M. (1964) Medical investigation of retinal vascular occlusion. Brit. med. J. ii, 1093.

Exton-Smith, A.N. (1959) Geriatric emergencies. Practitioner, 182, 418.

FINE, W. (1966) Epileptic syndromes in the elderly. Geront. clin. 8, 121.
FINE, W. (1967) Post-hemiplegic epilepsy in the elderly. Brit. med. J. i, 199.

FRY, H.J.H. (1964) Mortality in emergency surgical admissions over the age of 70 years. Brit. J. Surg. 51, 837.

Fullerton, J.M. (1965) Heart failure in old age. Brit. med.J. ii, 1432.

GARDEN, R.S. (1965) The casualty department and the accident service. Lancet, i, 901.

Heron, J.R. \& ANDerson, E.G. (1965) Concomitant cerebral and cardiac ischaemia. Lancet, ii, 405.

Howell, T.H. (1963) A Student's Guide to Geriatrics, p. 156. Staples Press, London.

Ledingham, J.G.G. (1964) Ethacrynic acid parenterally in the treatment and prevention of pulmonary oedema. Lancet, i, 1952.

McKeown, F. (1965) Pathology of the Aged. Butterworths, London.

Macmillan, D. \& Shaw, P. (1966) Senile breakdown in standards of personal and environmental cleanliness. Brit. med. J. ii, 1032.

MARShall, J. \& ReYNolds, E.H. (1965) Withdrawal of anticoagulants from patients with transient ischaemic cerebrovascular attacks. Lancet, i, 5.

Miller, H. (1967) Depression. Brit. med. J. i, 257.

Paulley, J.W. \& Hughes, J.P. (1960) Giant-cell arteritis. Brit. med. J. ii, 1562.

Pearce, J.M.S., Gubbay, S.S. \& Walton, J.N. (1965) Longterm anticoagulant therapy in transient cerebral ischaemic attacks. Lancet, $\mathrm{i}, 6$.

Pomerance, A. (1965) Pathology of the heart with and without cardiac failure in the aged. Brit. Heart J. 27, 697.

Prineas, J. \& Marshall, J. (1966) Hypertension and cerebral infarction. Brit. med. J. i, 14.

Registrar General (1966) Statistical Review of England and Wales, 1964, Part 1. H.M.S.O., London.

Royal College of Physicians of London (1966) Report of Committee on Accidental Hypothermia.

SaInSBURY, P. (1962) Suicide in later life. Geront. clin. 4, 161.

Schотт, A. (1964) Observations on digitalis intoxication: a plea. Postgrad. med.J. 40, 628.

SHELDON, J.H. (1960) On the natural history of falls in old age. Brit. med. J. ii, 1685 .

Sheldon, J.H. (1963) The effect of age on the control of sway. Geront. clin. 5, 129.

StevenS, R.S. (1963) Self-neglect in the elderly. Brit. J. ger. Pract. 2, 88.

Stevens, R.S. (1966) Geriatric emergencies. The Practitioner, $196,539$.

Stokes, W. \& NunN, L.C.A. (1964) A new effective diureticlasix. Brit. med. J. ii, 910.

STRANGE, S.L. (1963) Giant innocent gastric ulcer in the elderly. Geront. clin. 5, 171.

TAYLOR, G. (1964) The problem of hypothermia in the elderly. Practitioner, 193, 761.

THould, A.K. (1965) Coronary heart disease in the aged. Brit. med. J. ii, 1089.

Watts, C.A.H., Cawte, E.C. \& Kuenssberg, E.V. (1964) Survey of mental illness in general practice. Brit. med. J. ii, 1351.

Woodford-Williams, E. (1966) Diagnosis and management of pneumonia in the aged. Brit. med. J. i, 467.

YATES, P.O. (1964) A change in the pattern of cerebrovascular disease. Lancet, $\mathrm{i}, 65$. 